Acta Crystallographica Section A

Foundations of

Crystallography

ISSN 0108-7673

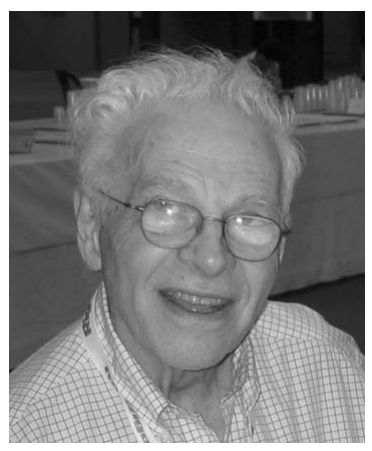

\section{Ewald Prize Award}

The IUCr is pleased to announce that Dr D. Sayre (Department of Physics, State University of New York, Stony Brook, NY 11794, USA) has been awarded the eighth Ewald Prize for the unique breadth of his contributions to crystallography, which range from seminal contributions to the solving of the phase problem to the complex physics of imaging generic objects by X-ray diffraction and microscopy, and for never losing touch with the physical reality of the processes involved.

The presentation of the Ewald Prize will be made during the Osaka Congress Opening Ceremony on 23 August 2008. 